DOI: 10.1002/adhm. 201300178

Submitted to

Full Paper

\title{
Multiwalled Carbon Nanotubes Hinder Microglia Function Interfering with Cell Migration and Phagocytosis
}

\author{
Juan C. Villegas ${ }^{1}$, Laura Álvarez-Montes ${ }^{2}$, Lidia Rodríguez-Fernández ${ }^{3}$, Jesús González ${ }^{4}$, \\ Rafael Valiente ${ }^{5}$, Mónica L. Fanarraga ${ }^{6}$ \\ ${ }^{1}$ Departamento de Anatomía y Biología Celular, Universidad de Cantabria-IFIMAV, 39011, \\ Santander. Spain. \\ ${ }^{2}$ Unidad de Microscopía Láser, IFIMAV, 39011, Santander. Spain. \\ ${ }^{3}$ SERMET, Universidad de Cantabria, 39005, Santander, Spain \\ ${ }^{4}$ MALTA-Consolider Team, CITIMAC, Facultad de Ciencias, Universidad de Cantabria, \\ 39005 Santander, Spain \\ ${ }^{5}$ Departamento de Física Aplicada, Facultad de Ciencias, Universidad de Cantabria, 39005 \\ Santander, Spain \\ ${ }^{6}$ Departamento de Biología Molecular, Universidad de Cantabria-IFIMAV, 39011, Santander. \\ Spain.
}

Keywords: Multiwalled carbon nanotubes, apoptosis, proliferation, migration, phagocytosis

The intranasal drug delivery route provides exciting expectations regarding the application of engineered nanomaterials as nano-medicines or drug-delivery vectors into the brain. Among nanomaterials, multi-walled CNTs (MWCNTs) are some of the best candidates for brain cancer therapy since they are well known to go across cellular barriers and display an intrinsic ability to block cancer cell proliferation triggering apoptosis. Our study reveals that microglial cells, the brain macrophages and putative vehicles for MWCNTs into the brain, undergo a dose-dependent cell division arrest and apoptosis when treated with MWCNTs. Moreover, we show that MWCNTs severely interfere with both, cell migration and phagocytosis in live microglia. These results lead to a re-evaluation of the safety of inhaled airborne CNTs and provide strategic clues of how to biocompatibilize MWCNTs to reduce brain macrophage damage and to develop new nanodrugs 


\section{Submitted to}

\section{Introduction}

The intranasal route allows some chemicals, small particles and nanomaterials to enter the brain more efficiently than administered systemically. ${ }^{[1,2,3]}$ Among others, manganese oxide, ${ }^{[4]}$ silver, ${ }^{[5]}$ cerium oxide, ${ }^{[6,7]}$ ferric ${ }^{[8]}$ and copper $^{[9]}$ oxide or titanium dioxide ${ }^{[10]}$ nanoparticles (NPs) have been detected in the brain after exposure by inhalation. Moreover, some of these nanomaterials have also been associated with neurotoxicity and neurodegeneration after intranasal administration. ${ }^{[9-12]}$ On the other hand, the intranasal administration route is so fast and direct that could be exploited to introduce nanomedicines into the brain to treat neurodegenerative diseases or brain cancer, avoiding the blood brain barrier (BBB).

This entry route to the central nervous system is still poorly understood, but according to the literature the nose-to-brain delivery is mediated by the olfactory bulb (OB) resident brain macrophages, known as microglial cells. ${ }^{[13]}$ These cells are continuously surveying the brain parenchyma, ${ }^{[14,15]}$ and are strongly chemoattracted by foreign bodies, invading pathogens and tumors. ${ }^{[16]}$ After intranasal administration of nanomaterials, microglial cells are first recruited to the $\mathrm{OB}$, where they phagocyte the inhaled particles, distributing throughout the brain parenchyma afterwards. ${ }^{[17,18]}$ Thus, microglia are key cells to vehicle nanotherapeutics into the brain.

Among all nanomaterials, carbon nanotubes (CNTs) are highly appealing in nanotechnology for their very interesting mechanical, thermal and electronic properties. CNTs can go across cellular barriers, including the $\mathrm{BBB}$, and can interact with tissues in living organisms and enter the cells. Thus they have an enormous potential in medicine as nanodelivers to introduce genes or drugs into the brain. ${ }^{[19-22]}$

CNTs have been claimed not to be inherently cytotoxic to human cells ${ }^{[23]}$ but might produce biosynthetic interactions that can interfere with different cellular mechanisms. In 


\section{Submitted to}

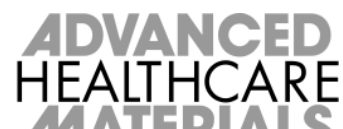

particular, these 1D nanostructures have been reported to interact with DNA ( 2 nm diameter), actin microfilaments $(7 \mathrm{~nm})$, and microtubules $(24 \mathrm{~nm})$. However, not all CNTs produce identical cellular effects suggesting intrinsic differences among these fibers. In particular, multi-walled CNTs (MWCNTs) display structural similarities to the protofilaments that constitute the microtubules $(8 \mathrm{~nm}),{ }^{[24,25]}$ and have been shown to intermingle with these inside the cells, assembling biosynthetic filaments that cause severe proliferation defects that trigger cell death. ${ }^{[25]}$ On the other hand, single-walled CNTs (SWCNTs), produce cortical actin reorganization and multinucleation in HeLa cells. ${ }^{[23,26]}$ These two different effects reveal that different species of nanotubes could selectively interact with either microtubules or actin filaments. And this interaction occurs because biological and synthetic filaments share numerous properties. They (i) display a similar length-to-width ratio, (ii) they both selfassemble, (iii) have all a high resiliency, and finally (iv) tend to form bundles that increase their strength. But, on the contrary to CNTs, microtubules and actin filaments are highly dynamic polymers that continuously undergo assembly and disassembly processes, and this dynamic behavior is crucial to play their roles in cell biology.

Herein we examine the cytoskeletal changes that occur in microglia when exposed to MWCNTs and the derived consequences. Our aim is to establish the effects of MWCNTs on the viability and function (migration and phagocytosis) of these brain macrophages.

\section{Results and Discussion}

\subsection{MWCNTs characterization and resuspension}

MWCNTs were synthesized, purified, characterized and dispersed as described elsewhere. ${ }^{[25]}$ Transmission electron-microscopy (TEM) imaging of the as-prepared MWCNTs revealed these CNTs displayed 3 to 12 walls, with outer diameter ranging from 5 
to $15 \mathrm{~nm}$, and inner diameter between 2.5 and $10 \mathrm{~nm}$ respectively (Figure 1). The Raman spectroscopy characterization of the as-prepared MWCNTs revealed a number of well characterized MWCNTs peaks. ${ }^{[27,28]}$ The dispersive disorder induced D band at $1330 \mathrm{~cm}^{-1}$, the tangential $\mathrm{G}$ band at $1586 \mathrm{~cm}^{-1}$ and the $\mathrm{D}^{\prime}$ band at $1614 \mathrm{~cm}^{-1}$ were observed. These were assigned using the symmetry analysis to the longitudinal optical (LO) mode close to Brillouin zone center $(\Gamma)$. Both, TEM and Raman spectroscopy techniques ruled out impurities or contaminants in these MWCNTs samples. ${ }^{[29]}$

We prepared a stable dispersion of MWCNTs in horse serum (HS) to be added to the culture media. HS is a standard additive in the medium and typically contains proteins and lipids shown to interact with the surface of various types of CNTs, including this particular type of MWCNTs. A stock resuspension of $60 \mu \mathrm{g} / \mathrm{mL}$ of MWCNTs in HS was prepared as reported elsewhere (see the Experimental section and Ref. 25). The $60 \mu \mathrm{g} / \mathrm{mL}$ stock solution was used as a ratio $1: 10$ or $1: 100 \mathrm{v} / \mathrm{v}$ dilution into the cell culture medium where MWCNTs aggregation or precipitation were not observed during the course of the experiments. Resuspended MWCNTs were stable for several days at $4^{\circ} \mathrm{C}$, and at least for $70 \mathrm{~h}$ at $37^{\circ} \mathrm{C}$ diluted in culture medium.

\subsection{Low MWCNTs dosages induce cytoskeletal-related cell division defects, while high}

\section{dosages produce $S$ phase cell cycle arrest}

Intracellular MWCNTs were confirmed by confocal Raman scattering and TEM (Figure 2). For the study we have used a cell line model named BV2, an immortalized murine microglial cell line, commonly used in many macrophage studies and which has been previously shown to efficiently internalize MWCNTs. ${ }^{[30]}$ The use of a cell line model in these experiments improves reproducibility and reduces primary cell culture variables (such as cell diversity, cell death due to tissue handling, individual animal differences, etc.). To obtain the Raman scattering spectra, the laser beam was focused on a spot of about $1 \mu \mathrm{m}^{2}$ localized 
within the cytoplasm of a $70 \mathrm{~h}$ MWCNT-treated cell (Figure S1, blue spot). Typical G and D peaks, together with fingerprints corresponding to the cellular proteins and the growing substrate (borosilicate glass) were observed (Figure 2a, red, indicated as "glass substrate"). These later peaks were also observable in control cells treated with HS (Figure 2a, black). Intracellular MWCNTs were also detectable by TEM on sections of $70 \mathrm{~h}$ MWCNT-treated cells (Figure 2b, S2). Although identifying single intracellular MWCNTs by TEM in cellular sections is highly improbable at the working dosages used, we were able to distinguish individual MWCNTs in various cell cytoplasms (Figure 2b), and also occasionally crossing the plasma membrane of microglia (Figure S2b). Intracellular bundles of MWCNTs similar to those previously characterized for other cell lines were also observed (Figure S2c). ${ }^{[25]}$ The fact that MWCNTs were observed individually in these cells indicates that MWCNTs were effectively dispersed in our culture medium and that these fibers were not engulfed as a micro-aggregates.

We investigated the phenotypes of these cells treated for $70 \mathrm{~h}$ with a final $0.6 \mu \mathrm{g} / \mathrm{mL}$ MWCNTs dose dispersed in the culture medium. For this purpose, cells were fixed, stained for nuclear DNA (blue channel) and actin (red channel), and examined by confocal microscopy. Projection images of treated microglia revealed that many cells in the culture contained fragmented DNA, indicative of cell death by apoptosis (Figure 3a, empty arrows). More interestingly, there were large numbers of cells apparently arrested in metaphase, displaying supernumerary chromosomes (Figure $3 \mathrm{a}$, filled arrows). This finding, known as polyploidy, often results in aberrant cell divisions leading to multi-nucleation or aneuploidy.

We next characterized by flow cytometry the distribution and total amount of DNA per cell. This is a broadly used technique to perform quantitative and qualitative analysis of the total DNA content per cell, in approximately 10.000 cells per experiment, allowing the simultaneous determination of the percentages of cells at each stage of the cell cycle, and the percentage of apoptotic cells (see further details in the Experimental section). ${ }^{[31]}$ Figure $3 \mathrm{~b}$ 
Submitted to

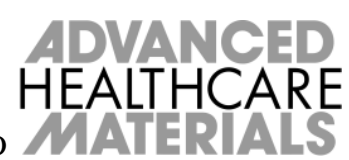

(left panel) displays the cell cycle profiles for the different microglial cell populations (the rough cell populations have been colored for simplicity). These profiles reveal that, in control cultures, most microglial cells were not undergoing cell division (approximately $70 \%$ of the total cell population, labeled as G1 and colored in red). Early dividing cells, undergoing DNA synthesis (S stage, yellow peak), represented approximately 15-20\%. And finally, dividing cells, containing twice the total DNA per cell (G2 stage, blue peak) represented less than 10\% of the total control cells population. In contrast, cells exposed to MWCNTs displayed dosedependent cell cycle distribution changes. Low MWCNT dosages $(0.6 \mu \mathrm{g} / \mathrm{mL})$ produced a patent misplacement of the cell cycle flow cytometry pattern, suggesting the existence of cells containing several nuclei or polyploidy (purple and green peaks) (Figure 3b). These findings indicated that MWCNTs could hinder cell division at the final stages of mitosis, allowing chromosomal duplication, but interfering with anaphase, telophase or cytokinesis. [32-36] While, on the other hand, high MWCNT concentrations in the culture medium $(6 \mu \mathrm{g} / \mathrm{mL})$ produced an earlier mitotic arrest at the $\mathrm{S}$ phase of the cell cycle (Figure 3b, bottom-left graph, yellow peak) and a severe DNA-fragmentation effect, a typical feature of apoptosis. We conclude this double cell-killing effect depends on the actual intracellular MWCNT concentrations. While low MWCNT numbers would mostly interfere with actin or microtubules, high MWCNT concentrations would invade the whole cell, including the nucleus. ${ }^{[37]}$ As CNTs have been reported to inhibit DNA synthesis ${ }^{[37]}$ and to destabilize the DNA structure, ${ }^{[38]}$ MWCNTs entry in the nucleus would interfere with DNA during replication, at the "S" (synthesis) stage of the cell cycle, leading to cell dead (Figure 3b). Thus, in both instances MWCNTs could trigger apoptosis, firstly, through the activation of the spindle assembly checkpoint, arresting cells in mitosis, and secondly, inhibiting DNA synthesis.

\subsection{Microglia cell migration is severely affected by MWCNTs}


Submitted to

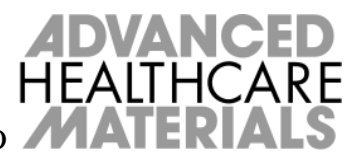

In macrophages, actin filaments play crucial roles in cell migration and phagocytosis, ${ }^{[40]}$ thus we investigated the effect of MWCNTs in both processes. We first quantified cell speed and motility in $70 \mathrm{~h}$ MWCNT-incubated cells performing time-lapse video microscopy. Manual tracking analysis (Figure 4, Video S1 \& S2) revealed an average speed in control cells of $0.72 \mu \mathrm{m} / \mathrm{min}(\mathrm{SD}=3.4)$, twice the speed of that observed for MWCNT-treated cells $(0.31 \mu \mathrm{m} / \mathrm{min})(\mathrm{SD}=2.6)$. Correspondingly, while control cells travelled an average total distance of $157 \mu \mathrm{m}$ during $3.5 \mathrm{~h}(\mathrm{SD}=34)$, MWCNT-treated microglia only moved a total average distance of $65 \mu \mathrm{m}(\mathrm{SD}=43)$ (Figure S3). The statistical comparison between these two sets of values revealed that MWCNTs significantly interfered with microglial cell speed and motility (with $t$ student parameters of 11.7 and 11.4, respectively, in both cases degrees of freedom DF $=96$ and $p=10^{-10}$ ). Similar speed differences were also observed in BV2 cells infected microglia in a $22 \mathrm{~h}$ video (see below). As far as we know, this is the first evidence in the literature demonstrating that CNTs interfere with cell migration.

\subsection{Microglia cell phagocytosis is also hindered by MWCNTs}

As explained above, phagocytic processes regardless of the organism or specific molecules concerned, are driven by a finely controlled rearrangement of the actin cytoskeleton. $^{[40]}$ Thus, to further confirm that MWCNTs were interfering with the actin filaments we examined the phagocytic capacity of these macrophages when exposed to a bacterial infection. MWCNT-treated and control BV2 cell cultures, were inoculated with low numbers of Listeria monocytogenes in the medium, a bacterium that causes the infection listeriosis. The microglial-bacterial interaction was followed by time-lapse video microscopy during 22 h. Figure 5a (top) shows how control microglial cells did not allow bacteria to grow in the culture plate (Video S3) while cultures that had been previously incubated with MWCNTs for $70 \mathrm{~h}$, displayed a conspicuous bacterial growth $22 \mathrm{~h}$ post-infection (Insets \# 4, and \# 5, arrow; Video S4). Quantification of bacterial growth (Figure 4b) corroborated these 


\section{Submitted to}

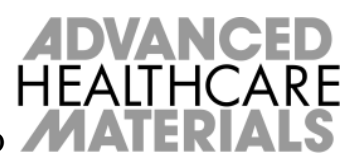

findings while revealing a dose-dependent effect. Therefore, these findings demonstrate that MWCNTs also impede the phagocytic capacity of microglia supporting the hypothesis that MWCNTs could interfere with actin filament dynamics.

\subsection{MWCNTs induce microglial multinucleation in primary cultures}

We also investigated in vitro if microglia were the target cells for MWCNTs in the OB. For this purpose we dissected, dissociated and cultured murine OB cellular components. These cells, namely neurons, macroglia and microglia, were exposed to $0.6 \mu \mathrm{g} / \mathrm{mL}$ MWCNTs in the culture medium for $70 \mathrm{~h}$ before fixation and processing (see further details in the Experimental section). Figure 6 shows the effects of the addition of MWCNTs in OB nerve cells in vitro. Confocal microscopy imaging revealed no obvious degenerative changes (such as DNA fragmentation of axonal retraction) in $\mathrm{OB}$ neurons at these incubation times, suggesting that MWCNTs were not toxic to neurons at these concentrations and exposure times.

On the other hand, microglial cells in MWCNT-treated cultures displayed a clear amoeboid morphology, characteristic of activated macrophages and were heavily loaded with MWCNTs as observed by differential interference contrast (DIC) microscopy (Figure 6, Inset \# 6). The large cytoplasmic vacuoles filled with black deposits indicated MWCNTs accumulation in the microglial cell cytoplasm (Inset \# 6, black arrow). Confocal microscopy imaging also showed a patent remodeling of the actin cytoskeleton where no filamentous actin (F-actin) was observed. Interestingly, microglial cell bi-nucleation (blue arrows) was also observed. These results confirm that, just as reported in vivo, ${ }^{[13,16]}$ in vitro OB microglial cells are also the target cells for MWCNTs and behave as highly active macrophages engulfing these nanofilaments.

Finally, microglial multi-nucleation was also investigated and reproduced in primary cultures of purified brain microglia. Figure 7a shows a confocal microscopy projection image 


\section{Submitted to}

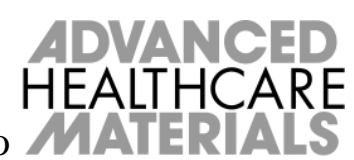

of three microglial cells, each displaying two nuclei after $70 \mathrm{~h}$ incubation with MWCNTs. Quantification of mono-nucleated vs. multi-nucleated cells demonstrated a statistically significant rise of $22 \%$ in multi-nucleation (a significant drop of mono-nucleated cells) in MWCNT-treated cultures. Since microglia cell fusion was not observed in time-lapse live cell videos, we concluded that this phenotype was the result of a late cell division defect. MWCNTs could be interacting biomimetically with the mitotic spindle microtubules as described for HeLa cells, ${ }^{[25]}$ or with the actin filaments of the contractile ring, inhibiting the progression of the cell cleavage and impeding the separation of the two daughter cells. The inhibition of the actin contractile ring, as described for other systems, ${ }^{[26,35-37]}$ typically produces a late G2 arrest that makes cells to terminate cell division abruptly bearing two nuclei. Hence these results also indicate that in brain purified macrophages these MWCNTs interact with actin, stabilizing these filaments in a similar fashion to that described for microtubules in HeLa cells. ${ }^{[25]}$ In addition, the patent reorganization of the cytoplasmic actin filaments $^{[39]}$ and the existence of small cytoplasmic compact DNA aggregates, just as observed for the BV2 cell line, confirmed apoptosis in these primary cultures of brain microglia (Figure 7a, arrows).

\section{Conclusions}

The development of drugs that can enter the brain bypassing the $\mathrm{BBB}$ is one of the present challenges in medicine and a key obstacle to treat malignant brain tumors or neurodegenerative diseases. The intranasal administration route, ideal for these purposes, depends on microglia as key players in the distribution of nanomaterials through the brain, since these cells are strongly attracted by foreign materials and tumors cells or invading pathogens. Among nanomaterials, MWCNTs could represent ideal candidates for brain cancer therapy. These fibers are well known to go across cellular barriers and display an intrinsic 


\section{Submitted to}

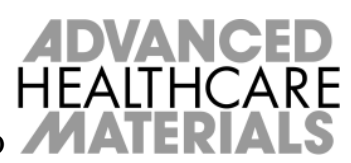

ability to block cancer cell proliferation triggering apoptosis by interacting with intracellular nanofilaments such as microtubules or actin. However, our work demonstrates that these properties are a double edge sword since MWCNTs severely impeded microglial vehiculization of carbon nanotubes towards the tumor site after intranasal administration.

On the other hand, these properties might result interesting when considering local brain pre- or post-surgical adjuvant therapy. There are several studies that suggest that microglia and brain macrophages are a hallmark of human malignant brain tumors and significantly contribute to the clinical course and bad prognosis of brain tumors. ${ }^{[41]}$ Thus local MWCNT therapy would mostly interfere with the tumor macrophages rather than other local cells (Figure 6), producing anti-tumoral effects in situ as shown for other tumors, ${ }^{[42]}$ while preserving intact the microglial immune-function in the rest of brain parenchyma. These results also provide new clues about the dosages, administration routes and modifications required to turn MWCNTs into more biocompatible brain drug delivery vectors. Finally, these results also urge to reconsider air-borne CNT associated neurotoxicity and neurodegeneration.

\section{Experimental Section}

MWCNTs characterization, functionalization and dispersion: MWCNTs were synthesized following the Catalytic Chemical Vapor deposition method as previously described. ${ }^{[29]}$ These particular MWCNTs have been fully characterized by various methods elsewhere. ${ }^{\left[{ }^{[5]}\right.}$ A stable MWCNTs suspension was obtained in HS after repeated cycles of vortex mixing followed by mild sonication (cycles of $2 \mathrm{~s}$ x 5 times, frequency of $38 \mathrm{kHz}$ ) as previously described. The stability of the suspension and the existence of aggregates were tested through the optical absorption spectra in the $400-800 \mathrm{~nm}$ range for $20 \mathrm{~min}$ after each sonication cycle. The suspension stability was checked by measuring the absorbance as a function of time up to 70 $\mathrm{h}$ for different wavelengths. ${ }^{[25]}$ A stock solution containing $0.140 \mathrm{mg}$ MWCNTs dispersed in 
$2.3 \mathrm{~mL}$ of HS was prepared (a $60 \mu \mathrm{g} / \mathrm{mL}$ ). Higher concentrations of MWCNTs were

impossible to disperse steadily. This MWCNT-HS dispersion was added to the culture. Unless otherwise indicated, cells were routinely treated with a final $0.6 \mu \mathrm{g} / \mathrm{mL}$ MWCNT dose in the culture medium. Identical amounts of total serum (final 10\% of both HS and bovine serum) were used in all experiments.

BV2 Cell Cultures: The microglial cell line model known as BV2 has been broadly characterized (Pokock, J. M.; Liddle, A.C. Prog. Brain Res. 2001, 132: 555-565). This cell line was originally produced by immortalization of murine microglia. This cell line was kindly provided by Dr. Pocock, UCL, National Hospital for Neurology \& Neurosurgery, London UK. BV2 cells grow in DMEM media containing $10 \%$ FCS at $37^{\circ} \mathrm{C}, 5 \% \mathrm{CO}_{2}$. Primary microglial cell cultures were prepared as previously described. ${ }^{[43]}$ Microglial cells were morphologically identified as described elsewhere. ${ }^{[43]}$

Optical and Raman Spectroscopy: Visible absorption spectra were recorded with Cary 50 and Cary 6000i spectrometers (Varian) operating in the $400-800 \mathrm{~nm}$ range. A quartz cuvette of 1 $\mathrm{cm}$ light path was filled with solutions of different concentrations of MWCNTS suspended in HS. The unpolarized Raman spectra were taken with a Horiba T64000 triple spectrometer in the backscattering geometry, using the $647 \mathrm{~nm}$ line of a Coherent Innova Spectrum 70C Ar$\mathrm{Kr}$ laser and a nitrogen-cooled CCD (Jobin-Yvon Symphony) with a confocal microscope for detection. The laser beam was focused down to $1 \mu \mathrm{m}^{2}$ spot with a 100X objective and kept the power on the sample below $2 \mathrm{~mW}$ to avoid laser-heating effects on the probed material and the concomitant softening of the observed Raman peaks. MWCNTs produce a characteristic Raman spectrum distinguishable of SWCNTs spectrum. ${ }^{[27-28]}$ The radial breathing modes (RBM), a Raman feature associated with a small diameter inner tube, is not common and can only sometimes be observed when a good resonance condition is established. The RBM signal from large diameter tubes is usually too weak to be observable and the ensemble average of inner tube diameter broadens the signal. 
Submitted to

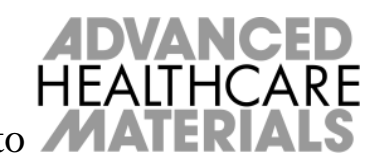

Flow Cytometry: This technique allows the possibility of multiparameter measurements at the cellular level in thousands of cells per second. ${ }^{[31]}$ Flow cytometry was performed on a suspension of fixed BV2 cells stained with Hoechst, a dye that produces a quantitative staining of DNA, using a Becton Dickinson FACS CantoII equipment.. This technique was used to determine a blockage in cell proliferation (the DNA content per cell is doubled during the cell cycle) and also to quantify the fractional DNA content ("sub-G1" peak), indicative of apoptosis. Further details of the technique can be found in Ref. 31. Analysis was performed on an average of 10.000 cells per condition (HS-control or HS-MWCNT-treated cells). Data quantification was obtained using the FACS Diva software (Becton Dickinson, NJ, USA). Analysis has been performed in three sets of experiments at the given concentrations.

Transmission Electron Microscopy: Morphological characterization of the as-produced MWCNTs was performed in a JEOL JEM 2100 microscope operating at $120 \mathrm{kV}$. Samples for TEM were prepared as previously described using ethanol as dispersant and omitting the sample centrifugation steps. ${ }^{[25]}$ A drop of this suspension was adsorbed onto a Lacey copper grid. Electron microscopy on cells was performed on $70 \mathrm{~nm}$ Araldite sections of pellets of BV2 cells fixed with $1 \%$ glutaraldehyde in $0.12 \mathrm{M}$ phosphate buffer, washed in $0.12 \mathrm{M}$ phosphate buffer, post-fixed in $1 \%$ buffered osmium tetroxide, dehydrated in a graded acetone series and embedded in Araldite observed with a JEOL JEM 1011 microscope. Sections were mounted on copper grids and stained with lead citrate and uranyl acetate.

Immunostaining and Confocal Microscopy Imaging: Cells were fixed in $1 \%$ glutaraldehyde. Antibodies used were anti- $\alpha$-tubulin (B512) (Sigma-Aldrich) combined with a secondary goat anti-mouse IgG antibody conjugated with Alexa Fluor 488 (Molecular Probes, Invitrogen). Actin was stained with Phalloidin-Tetramethylrhodamine B isothiocyanate (Sigma-Aldrich) and DNA (nucleus and chromosomes) with Hoechst dye (Bis-benzimide) (Sigma-Aldrich). Confocal microscopy images were obtained with a Nikon A1R confocal 
Submitted to

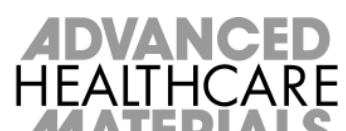

microscope and processed with the NIS-Elements Advanced Research software. All confocal cell images are pseudo-colored.

Live-Cell Imaging Techniques and Time-Lapse Video Microscopy Experiments. Bacterial phagocytosis: MWCNTs were washed from the culture before live-cell imaging. The cell migration speed and total track lengths were both measured on $3.5 \mathrm{~h}$ time-lapse movies obtained at 5 frames/min. Cells were incubated with MWCNTs during $70 \mathrm{~h}$ and then washed before live cell imaging. This was performed on a Nikon Eclipse Ti live-cell station, using a 20X Nikon N.A. 0.45. Cell tracking analysis was performed with the NIS-Elements software. Trajectory identification was performed manually on at least 200 individual cells per condition frame by frame. Infected cultures were imaged during $22 \mathrm{~h}$ (at 5 frames/min). Quantifications in Figure 5b were made on random images fields obtained at the indicated times with the NIS-Elements software. BV2 control and treated cell cultures were incubated with L. monocytogenes to provoke microglial activation and bacterial phagocytosis. Microglial cultures were exposed to bacteria for $1 \mathrm{~h}$ without antibiotic. Next, a bacteriostatic gentamicin dose was added to the cultures, allowing a minor time-dependent bacterial recovery. Bacterial density in cultures was measured in three random fields of video images taken at the indicated time points in 3 different cultures fields. Bacterial cells were quantified using the NIS-Elements software in 3 ROIs of $12 \square \mathrm{m}^{2}$ per photogram at the indicated times.

Statistical analysis: Unpaired two-tailed Student's $t$ tests were used for the statistical analyses of the differences between control and treated cell results. Three sets of experiments were used for each studied condition. SD stands for Standard Deviation. 


\section{Supporting Information}

Supporting Information is available online from the Wiley Online Library or from the author.

\section{Acknowledgements}

We thank Prof. J. C. Zabala for his support and helpful scientific discussions. We thank Dr. Alvarez for her help with the infection experiments and Dr. Flahaut for providing the MWCNTs. We are grateful to the Nikon A1R Laser Microscopy Unit of the IFIMAV Institute for the electron microscopy and confocal/time-lapse microscopy. This work has been supported by the Spanish MINECO under Projects ref. MAT2012-38664-C02-01; BFU201018948, MALTA Consolider-Ingenio ref. CSD2007-00045.

[1] M. Fazil, S. Shadab Baboota, J. K. Sahni, J. Ali. J. Drug Target. 2012, 20, 97-113.

[2] T. Sakane, S. Yamashita, N. Yata, H. Sezaki. J. Drug Target. 1999, 7, 233-240.

[3] M. Fazil, S. Md, S. Haque, M. Kumar, S. Baboota, J. K. Sahni, J. Ali. Eur. J. Pharm. Sci. 2012, 47, 6-15.

[4] A. Elder, R. Gelein, V. Silva, T. Feikert, L. Opanashuk, J. Carter, R. Potter, A. Maynard, Y. Ito, J. Finkelstein, G. Oberdörster. Environ. Health Perspect. 2006, 114, 11721178.

[5] M. B. Genter, N. C. Newman, H. G. Shertzer, S. F. Ali, B. Bolon. Toxicol. Pathol. 2012, 40, 1004-1013.

[6] A. Cimini, B. D'Angelo, S. Das, R. Gentile, E. Benedetti, V. Singh, A. M. Monaco, S. Santucci, S. Seal. Acta Biomater. 2012, 8, 2056-2067.

[7] L. Geraets, A. G. Oomen, J. D. Schroeter, V. A. Coleman, F. R. Cassee. Toxicol. Sci. 2012, 127, 463-473. 
Submitted to

[8] B. Wang, W. Y. Feng, M. Wang, J. W. Shi, F. Zhang, H. Ouyang, Y. L. Zhao, Z. F.

Chai, Y. Y. Huang, Y. N. Xie, H. F. Wang, J. Wang. Biol. Trace Elem. Res. 2007, 118, 233243.

[9] L. Zhang, R. Bai, Y. Liu, L. Meng, B. Li, L. Wang, L. Xu, L. Le Guyader, C. Chen. Nanotox. 2012, 5, 562-575.

[10] G. Oberdörster, A. Elder, A. Rinderknecht. J. Nanosci. Nanotechnol. 2009, 9, 49965007.

[11] J. Wang, C. Chen, Y. Liu, F. Jiao, W. Li, F. Lao, Y. Li, B. Li, C. Ge, G. Zhou, Y. Gao, Y. Zhao, Z. Chai. Toxicol. Lett. 2008, 183, 72-80.

[12] T. T. Win-Shwe, H. Fujimaki. Int. J. Mol. Sci. 2011, 12, 6267-6280.

[13] X. Zhuang, X. Xiang, W. Grizzle, D. Sun, S. Zhang, R. C. Axtell, S. Ju, J. Mu, L. Zhang, L. Steinman, D. Miller, H. G. Zhang. Mol. Ther. 2011, 19, 1769-1779.

[14] A. Nimmerjahn, F. Kirchhoff, F. Helmchen. Science 2005, 308, 1314-1318.

[15] L. J. Smithson, M. D. Kawaja, M. D. J. Neurosci. Res. 2010, 88, 858-865.

[16] F. Lazarini, M. M. Gabellec, N. Torquet, P. M. Lledo. J. Neurosci. 2012, 32, 36523664.

[17] Y. Wang, B. Wang, M. T. Zhu, M. Li, H. J. Wang, M. Wang, H. Ouyang, Z. F. Chai, W. Y. Feng, Y. L. Zhao. Toxicol. Lett. 2011 205, 26-37.

[18] L. R. Hanson, W. H. Frey. J. Neuroimmune Pharmacol. 2007, 2, 81-86.

[19] A. Bianco, K. Kostarelos, M. Prato. Curr. Opin. Chem. Biol. 2005, 9, 674-679.

[20] J. M. Schnorr, T. M. Swager. Chem. Mater. 2011, 23, 646-657.

[21] J. Ren, S. Shen, D. Wang, Z. Xi, L. Guo, Z. Pang, Y. Qian, X. Sun, X. Jiang. Biomaterials. 2012, 33, 3324-3333.

[22] X. Luo, C. Matranga, S. Tan, N. Alba, X. T. Cui. Biomaterials. 2011, 32, 6316-6323.

[23] H. N. Yehia, R. K. Draper, C. Mikoryak, E. K. Walker, P. Bajaj, I. H. Musselman, M. C. Daigrepont, G. R. Dieckmann, P. Pantano. J. Nanobiotech. 2007, 5:8 
[24] C. Z. Dinu, S. S. Bale, G. Zhu, J. S. Dordick JS. Small. 2009 5, 310-315.

[25] L. Rodriguez-Fernandez, R. Valiente, J. Gonzalez, J.C. Villegas, M. L. Fanarraga, ACS Nano. 2012, 6, 6614-25.

[26] B. D. Holt, P. A. Short, A. D. Rape, Y. L. Wang, M. F. Islam, K, N. Dahl. ACS Nano. 2010. 4, 4872-4878.

[27] E. F. Antunes, A. O. Lobo, E. J. Corat, V. J, Trava-Airoldi, A. A. Martin, C. Verissimo. Carbon. 2006, 44, 2202-2211.

[28] S. Dresselhaus, G. Dresselhaus, R. Saito, A. Jorio. Phys. Rep. 2005, 409, 47-99.

[29] E. Flahaut, Ch. Laurent, A. Peigney. Carbon. 2005, 43, 375-383.

[30] B. Kateb, V. Yamamoto, D. Alizadeh, L. Zhang. H. M. Manohara, M. J. Bronikowski, B. Badie. Methods Mol. Biol. 2010, 651, 307-17.

[31] D. Wlodkowic, W. Telford, J. Skommer, Z. Darzynkiewicz. Methods Cell Biol. 2011, $103,55-98$.

[32] L. Gonzalez, I. Decordier, M. Kirsch-Volders. Biochem. Soc. Trans. 2010, 38, 16911697.

[33] D. Cimini, D. Fioravanti, C. Tanzarella, F. B. Degrassi. Chromosoma. 1998, 107, 479485

[34] M. Pardo, P. Nurse. Science. 2003, 6, 1569-1574.

[35] S. N. Martineau, P. R. Andreassen, R. L. Margolis. J. Cell Biol. 1995, 131, 191-205.

[36] M. Bottini, S. Bruckner, K. Nika, N. Bottini, S. Belluci, A. Magrini, A. Bargamaschi, T. Mustelin. Toxicol. Lett. 2006. 160, 121-126.

[37] M. Desouza, P. W. Gunning, J. R. Stehn. Bioarchitecture. 2012, 1, 75-87.

[38] W. P. Roos, B. Kaina. Trends Mol. Med. 2006, 12, 440-50.

[39] X. Li, Y. Peng, J. Ren, X, Qu. Proc. Natl. Acad. Sci. U.S.A. 2006, 103, 19658-19663.

[40] R. C. May, L. M. Machesky. J Cell Sci. 2001, 114, 1061-1077. 
[41] J. R. Engler, A. E. Robinson, I. Smirnov, J. G. Hodgson, M. S. Berger, N. Gupta, C. D. James, A. Molinaro, J. R. Phillips. PLoS One. 2012, 7, e43339.

[42] M. Yang, J. Meng, X. Cheng, J. Lei, H. Guo, W. Zhang, H. Kong, H. Xu. Theranostics. 2012, 2, 258-270.

[43] M. L. Fanarraga, J. Villegas, G. Carranza, R. Castaño, J. C. Zabala. Exp Cell Res. $2009315,535-541$. 


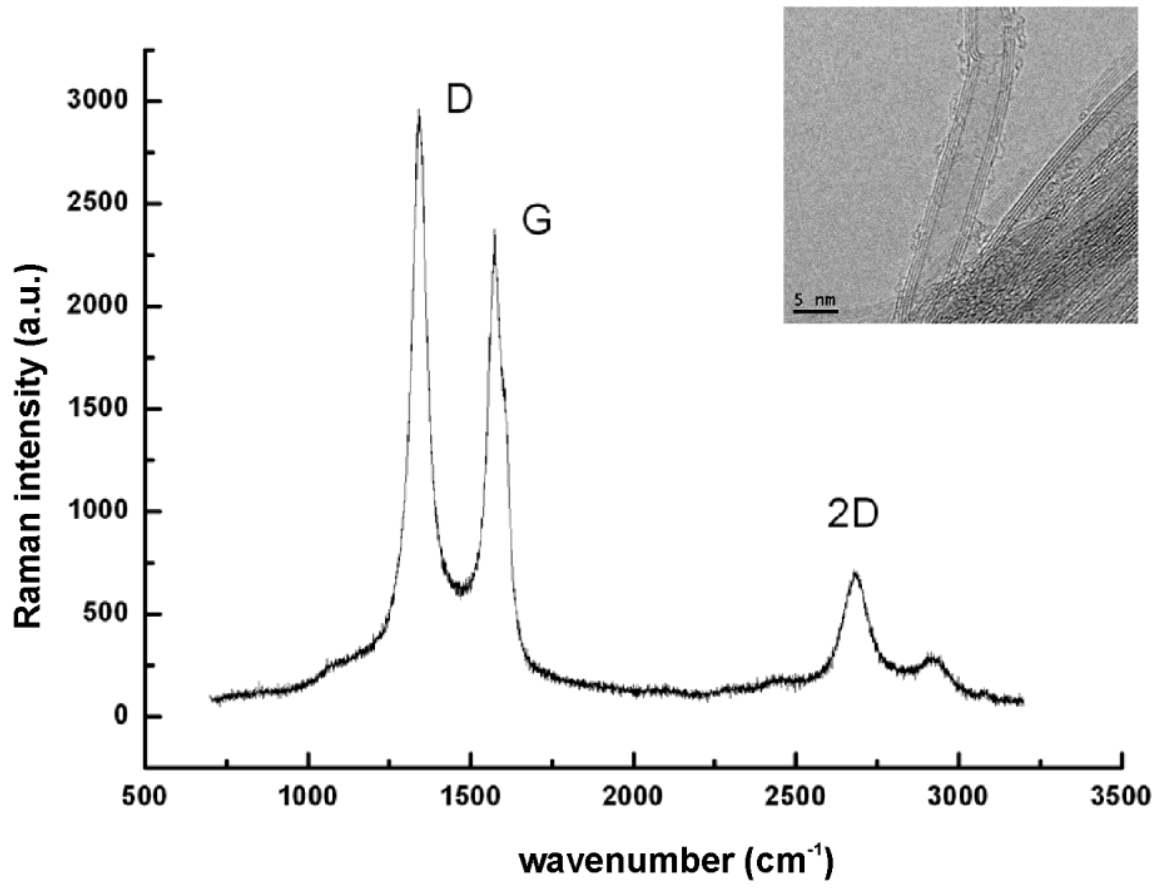

Figure 1. a) Room temperature Raman spectrum of the as-prepared MWCNTs using the 647 $\mathrm{nm}$ line of an $\mathrm{Ar}-\mathrm{Kr}$ laser. The main peaks are labeled as D, G, and 2D (see text). b) HRTEM image of the as-prepared MWCNTs. Absence of undesired impurities in MWCNTs is verified by both techniques. 


\section{Submitted to}

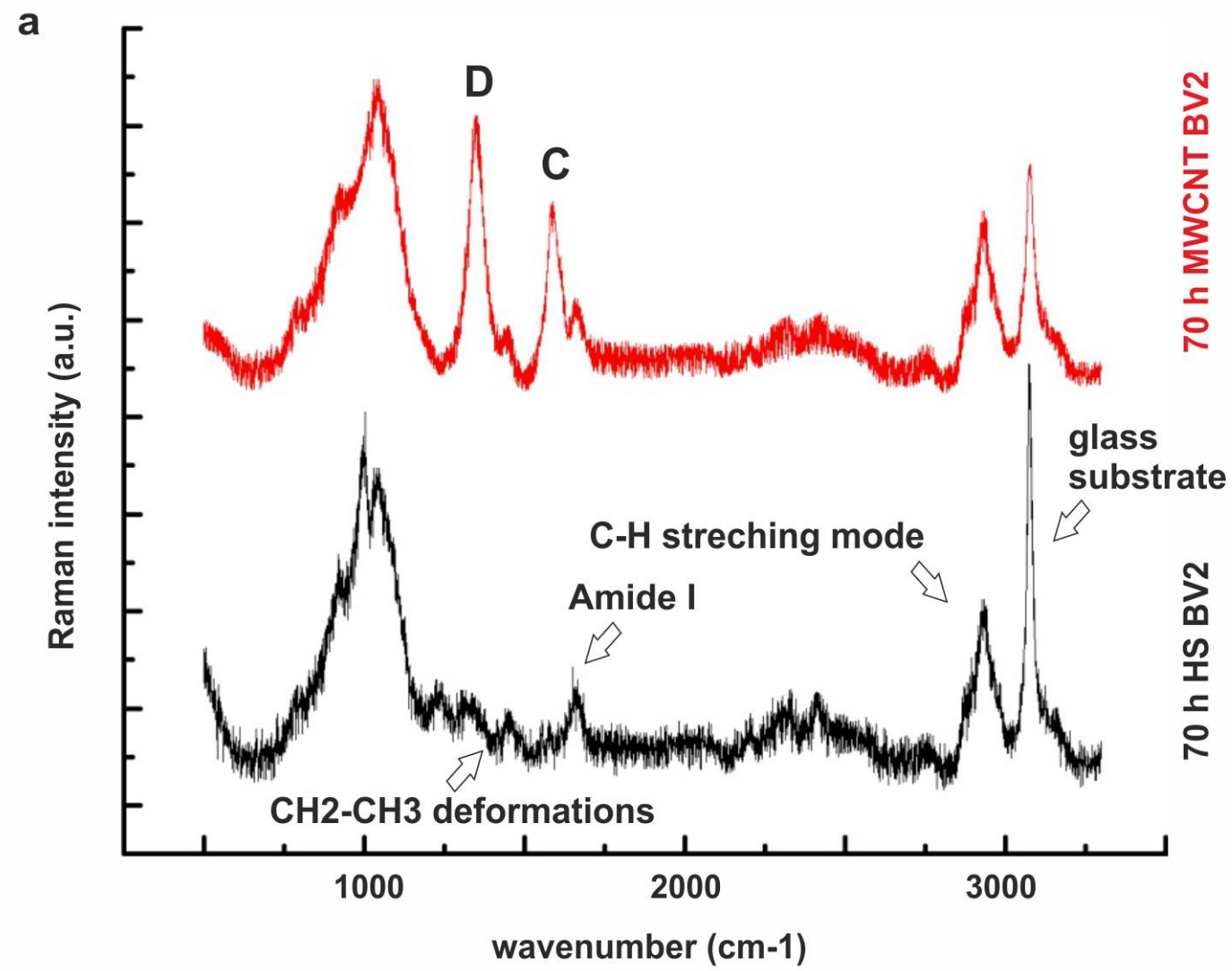

b

C
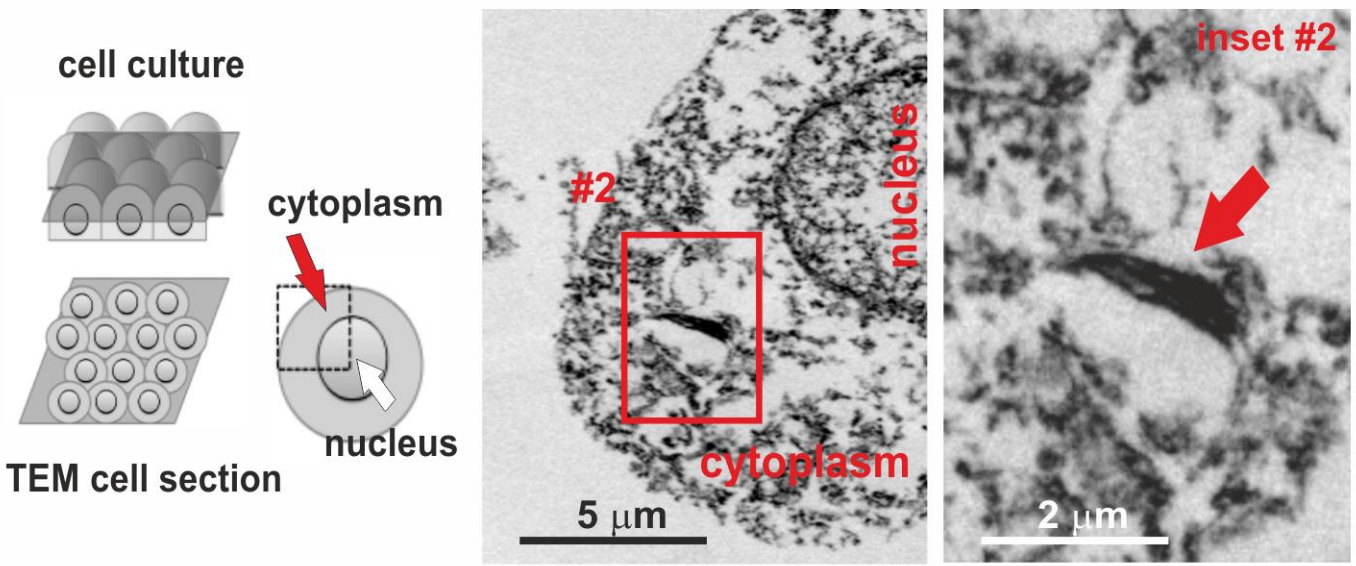

Figure 2. a) Raman scattering experiments performed on the cytoplasm of control $70 \mathrm{~h}$ control and MWCNT-treated microglial cells (black and red profiles, respectively). The spectrum displays the typical fingerprints of MWCNTs together with feature peaks that correspond to cellular proteins and the growing substrate (borosilicate glass coverslip) (See Figure S1). b) TEM section of a microglial cell. (Inset \# 1) Individual MWCNTs are observed inside the cell cytoplasm within the nuclear cleft. (Inset \# 2). Two intracellular filaments displaying different diameters are indicated, (i) a microtubule (empty arrow, $24.3 \mathrm{~nm}$ ), and (ii) a MWCNTs (filled red arrow, $7.85 \mathrm{~nm}$ ). 


\section{Submitted to HEALTHCARE}

a

nuclear DNA/chromosomes/actin
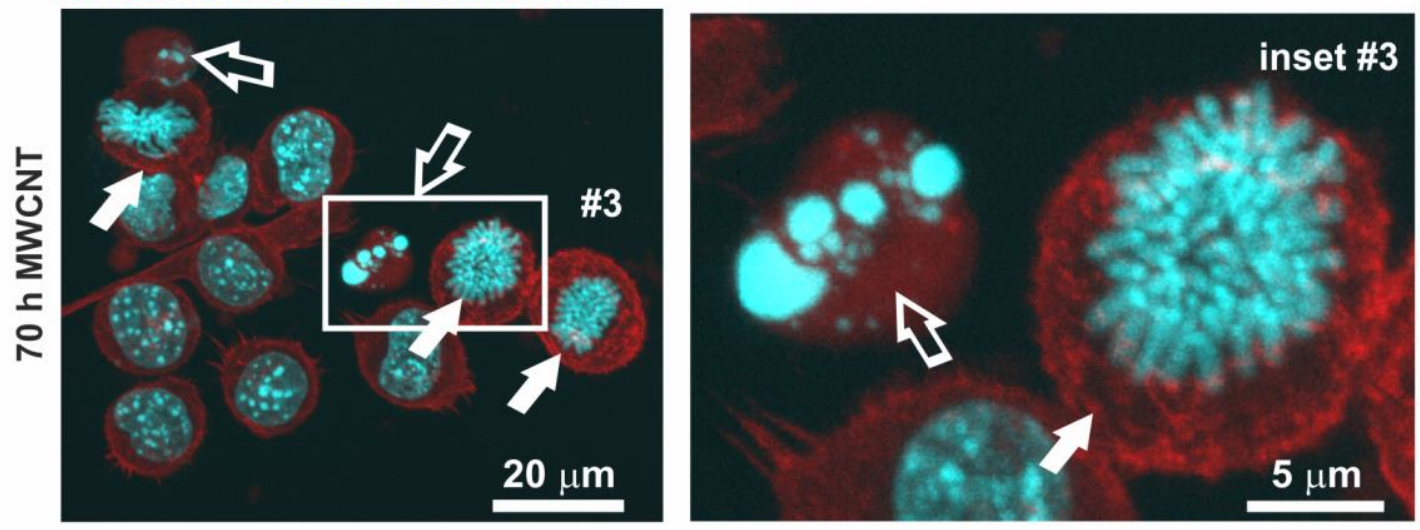

b

cell cycle

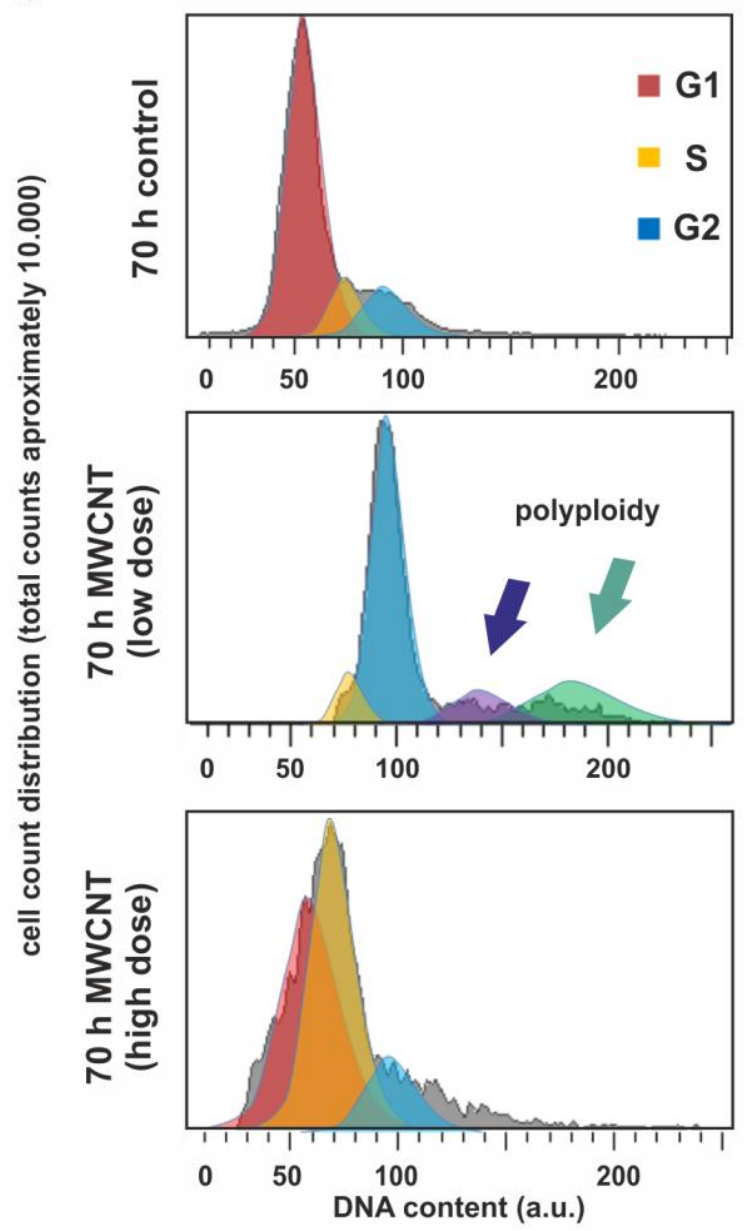

DNA fragmentation (apoptosis)
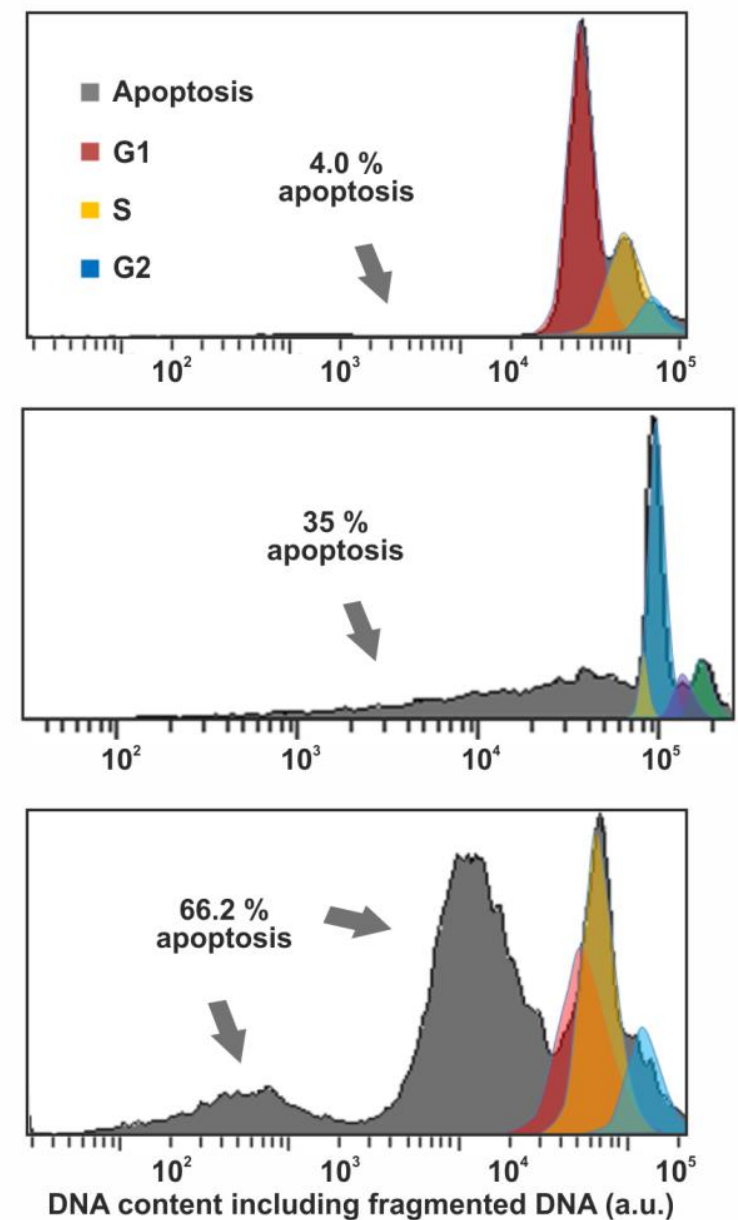

Figure 3. a) Confocal microscopy projection images of $70 \mathrm{~h}$ MWCNT-treated BV2 cells stained for nuclear DNA (blue channel) and actin (red channel). DNA deposits indicative of fragmentation and cell death by apoptosis is observed (Inset \# 3, empty arrows). Several metaphase cells apparently arrested in the middle of mitosis and displaying polyploidy (highly increased number of chromosomes) are indicated (filled arrows). b) Flow-cytometry cell cycle profiles of microglia labeled with Hoechst. Different cell cycle stages have been outlined and colored as indicated. (top graph) Typical cell cycle of microglia control cells. Non-dividing cells $(\mathrm{G} 1$, red peak) represent approximately $70 \%$ of the total cell population. (mid, bottom graphs) Flow-cytometry cell cycles of cultures incubated with final concentrations of 0.6 


\section{Submitted to}

$\mu \mathrm{g} / \mathrm{mL}$ and $6 \mu \mathrm{g} / \mathrm{mL}$ (low and high dose respectively) of MWCNTs in the medium. Low MWCNT dosages produced a patent increase in polyploidy/multi-nucleation $(3.5 \%$ of the cells) and a significant rise in the apoptotic rate (grey). These charts also reveal how large MWCNT concentrations in the culture medium severely interfere with the DNA synthesis process, leading to a patent S cell cycle arrest (37.5\% compared to $16.4 \%$ in controls, yellow peak) and to a massive cell death by apoptosis (grey). (Plots: $\mathrm{X}$ axis: total DNA content per event; Y axis: number of total events). 


\section{ADVANCED \\ HEALTHCARE \\ Submitted to MATERIALS}

a

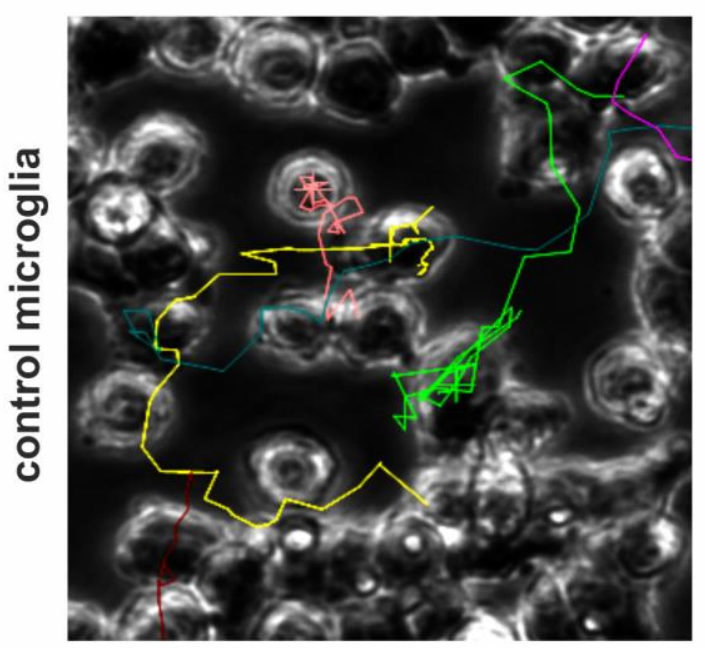

b

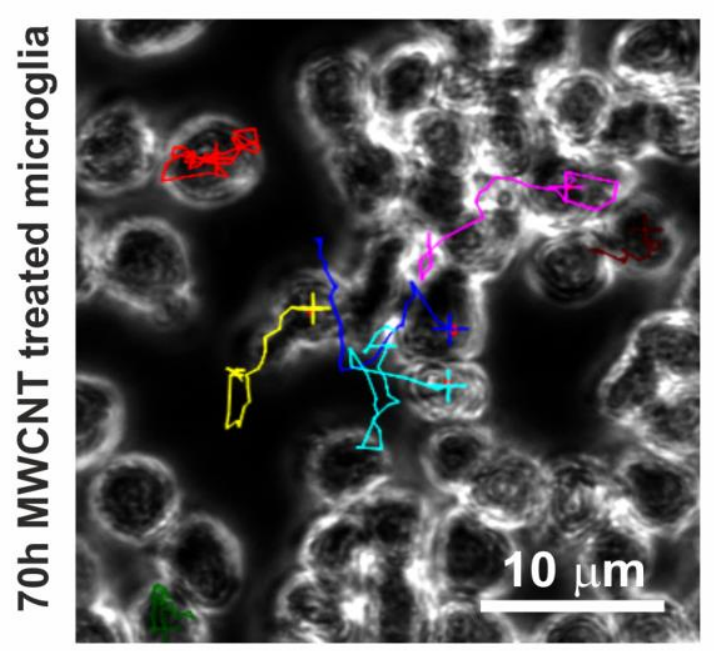

C

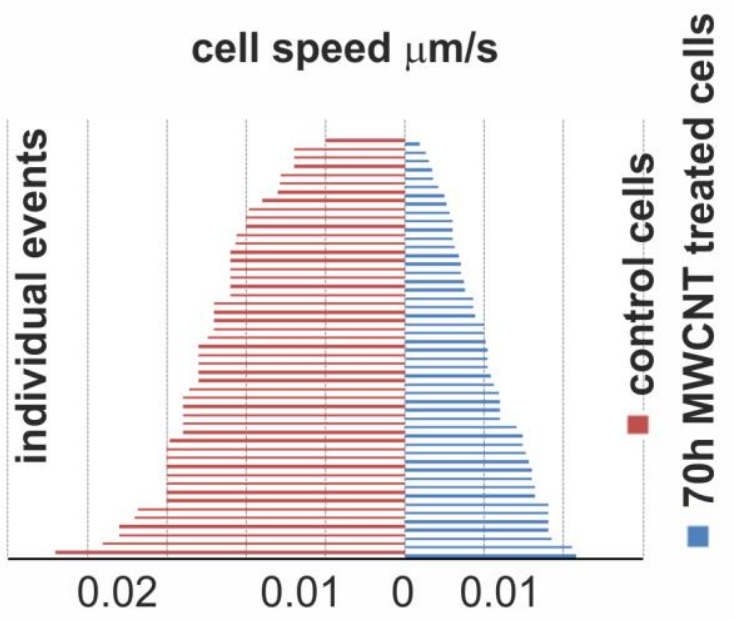

Figure 4. a) Sample $3.5 \mathrm{~h}$ tracking trajectories of control and MWCNT-treated microglial cells. Trajectories from different cells are labeled in different colors (See also Figure S3). b) Representation of individual cell speeds for control cells (right) and MWCNT-treated microglial cells (left). (See also the corresponding time-lapse videos S1 \& S2 available as Supporting information). 


\section{ADVANCED \\ HEALTHCARE \\ Submitted to MATERIALS}

a
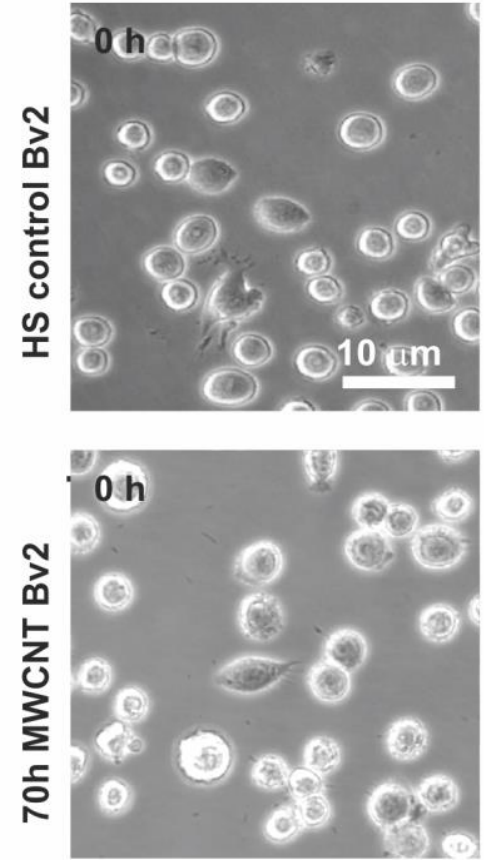
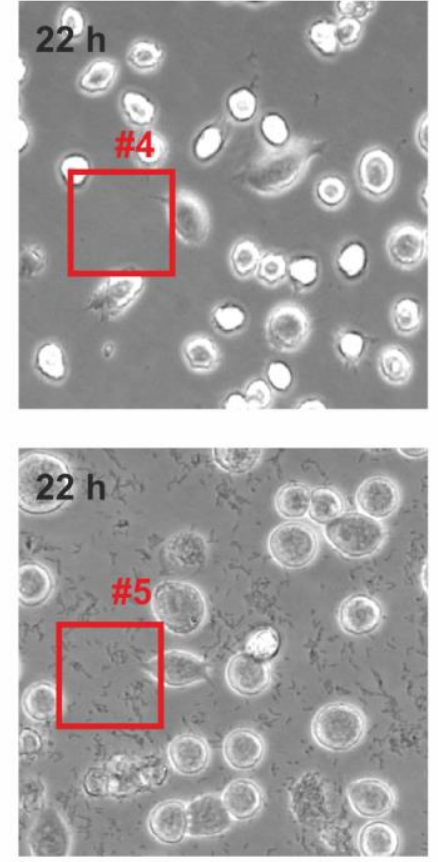

inset \#4
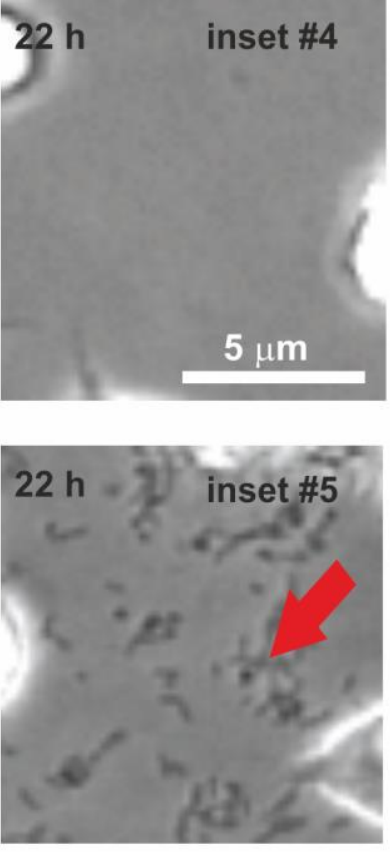

b

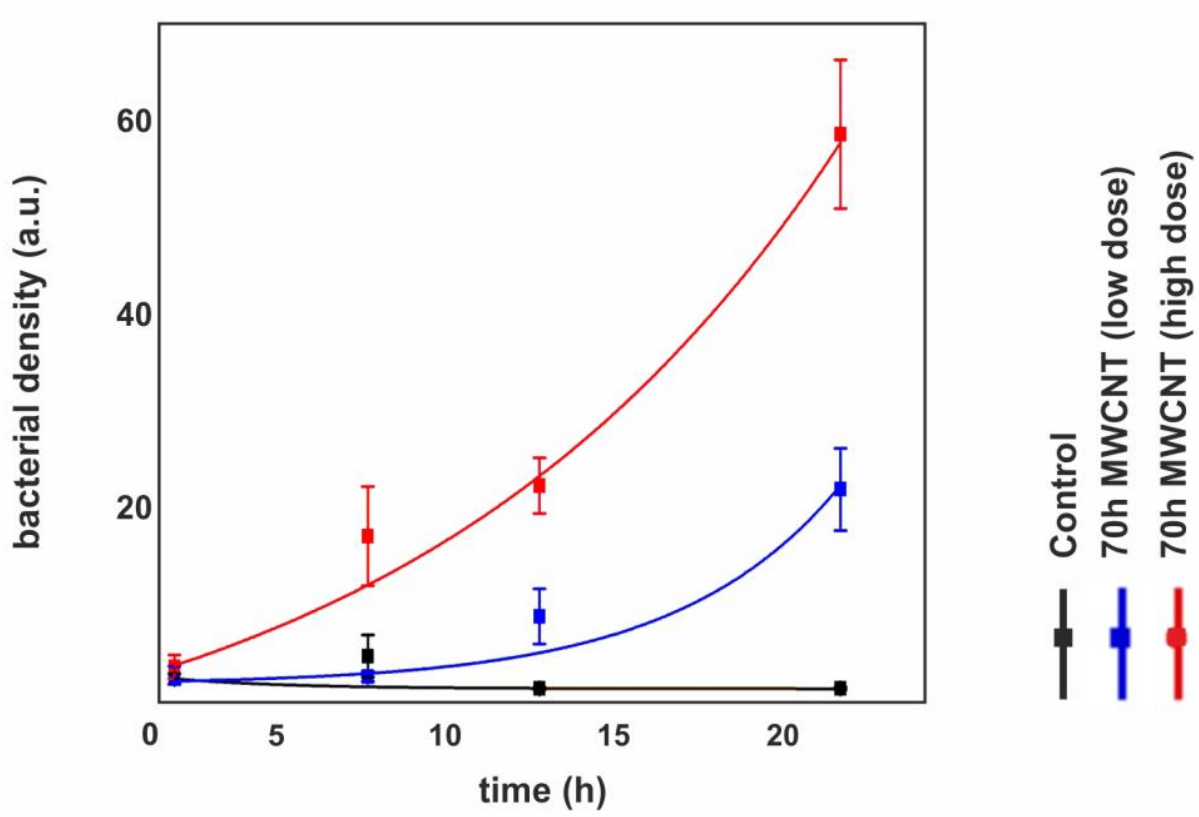

Figure 5. Microglial response to bacterial infection after $70 \mathrm{~h}$ incubation with MWCNTs. a) Single microscopy images of a $22 \mathrm{~h}$ time-lapse video obtained of microglial cell cultures infected with $\mathrm{L}$. monocytogenes at $\mathrm{t}=0$ and $\mathrm{t}=22 \mathrm{~h}$ post infection (See also time-lapse video S3 \& S4 available as Supporting Information). Insets \#4 and \#5 show bacterial growth in the culture $22 \mathrm{~h}$ post infection (arrow). b) Representation of the bacterial growth kinetics in these cultures at the indicated times. Control cells show a highly efficient bacterial clearance capacity, while macrophages treated with both, low and high dosages of MWCNTs for $70 \mathrm{~h}$ in the culture medium were significantly less successful destroying bacteria. 


\section{ADVANCED \\ HEALTHCARE \\ Submitted to MATERIALS}

mirotubules/nuclear DNA
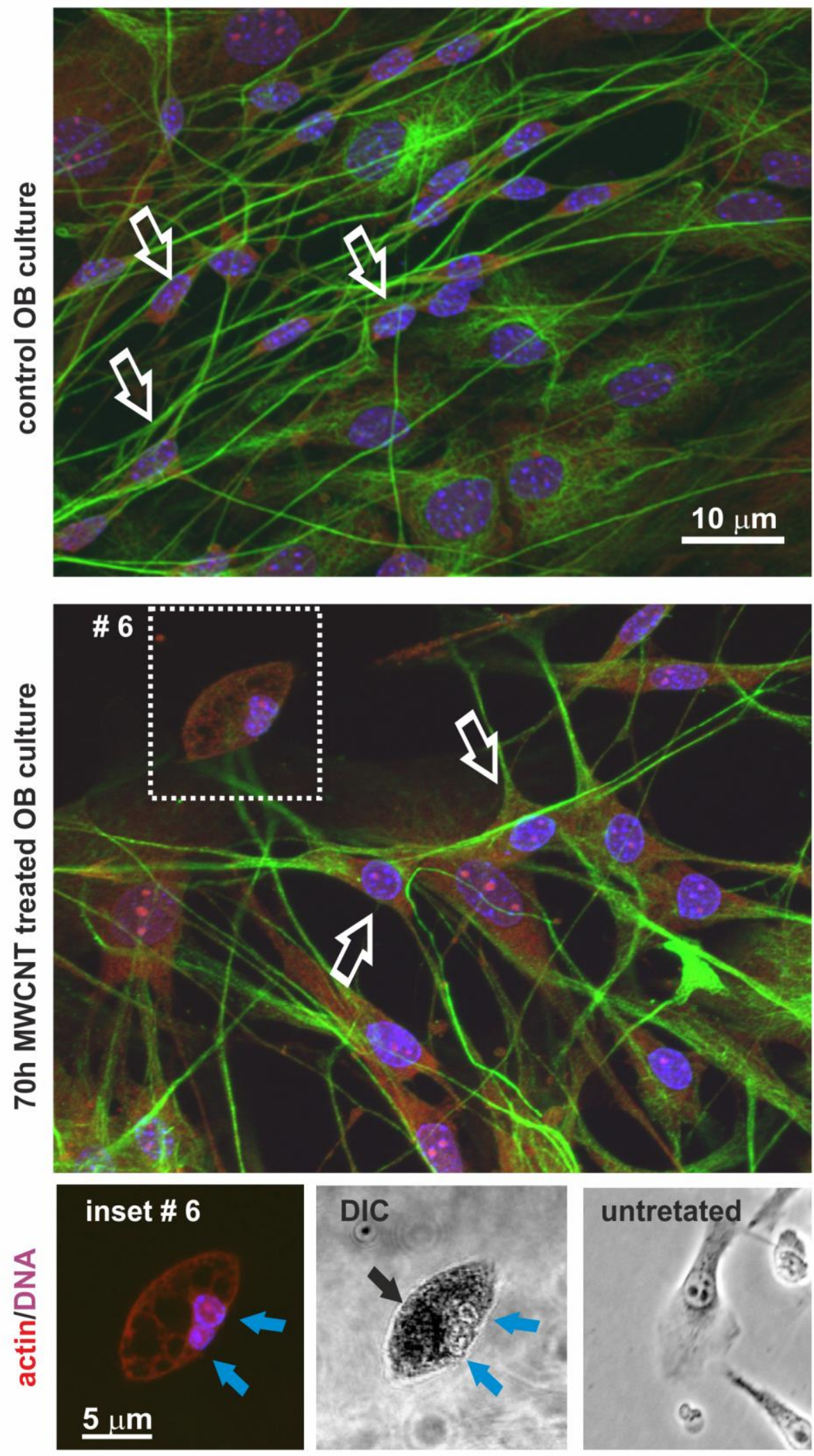


\section{Submitted to}

Figure 6. Confocal microscopy projection images of cells cultured from OB and treated with HS or MWCNTs for $70 \mathrm{~h}$. No obvious degenerative changes such as nuclear DNA

fragmentation are observed in neurons (empty arrows). Conversely, microglial cells appeared highly vacuolated. (\# 6). A disorganized microtubule distribution and binucleation (blue filled arrows) are observed. (Inset \# 6, right) Same cell observed by differential interference contrast (DIC) containing large deposits of MWCNTs in the cell cytoplasm (black arrow). A control untreated microglial cell is shown on the bottom right panel. 


\section{Submitted to \\ HEALTHCARE}

a $\quad 70 \mathrm{~h}$ MWCNT treated OB microglia nuclear DNA/actin

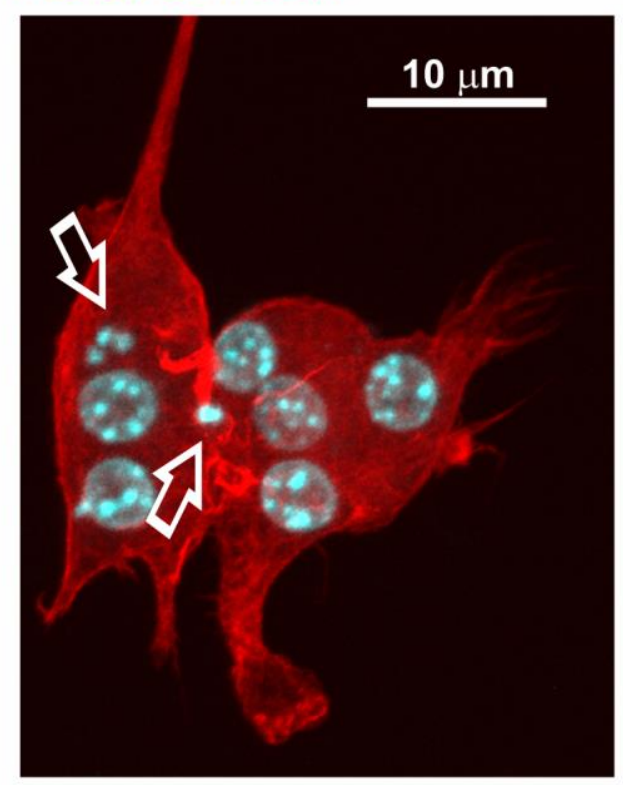

b
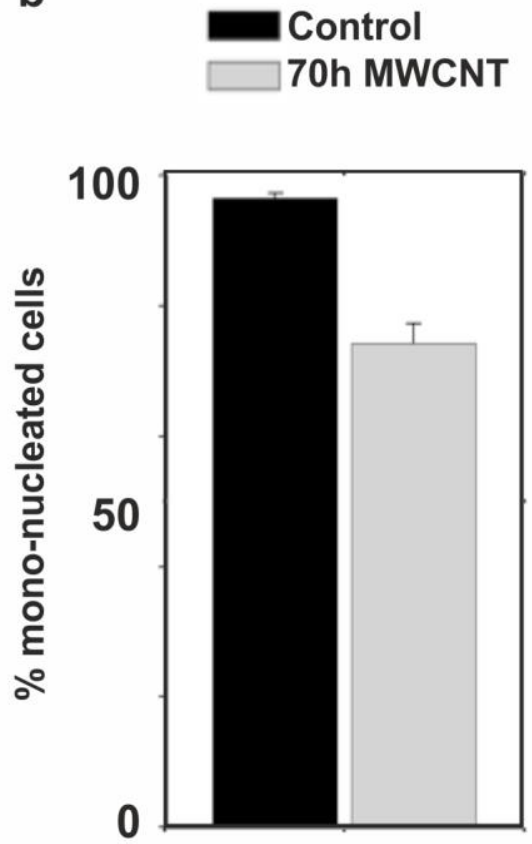

Figure 7. a) Confocal microscopy projection images of purified brain microglial cells treated with MWCNTs for $70 \mathrm{~h}$ and stained for actin (red channel) and nuclear DNA (blue channel). Features of cell death by apoptosis such as F-actin disorganization and the presence of small intracellular compact DNA masses are observed (arrows). b) Quantification of the percentages of mono-nucleated Vs multi-nucleated cells revealed a significant increase $(\mathrm{t}=$ $4.72 ; \mathrm{p}=3 \times 10^{-5}$; degrees of freedom, $\mathrm{DF}=39$ ) in microglial cell multi-nucleation in primary brain cultures treated with MWCNTs. 


\section{Submitted to

The table of contents

Our study reveals that microglial cells undergo a dose-dependent cell division arrest and apoptosis when treated with MWCNTs. We show in live microglia how MWCNTs severely interfere with both, cell migration and phagocytosis. These results provide strategic clues of how to biocompatibilize MWCNTs to reduce the damage in brain macrophages to develop new nanodrugs based on MWCNTs.

Keyword Multiwalled carbon nanotubes, apoptosis, proliferation, migration, phagocytosis

J. C. Villegas, L. Álvarez-Montes, L. Rodríguez-Fernández, J. González, R. Valiente, M. L. Fanarraga

Multiwalled Carbon Nanotubes Hinder Microglia Function Interfering with Cell Migration and Phagocytosis

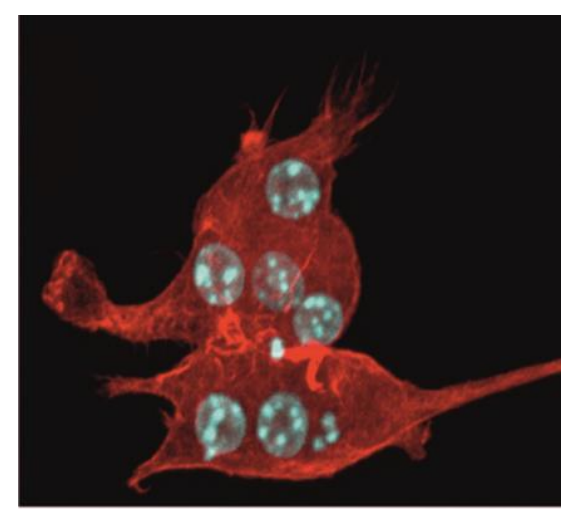

